\title{
O SOFRIMENTO E A DOR COMO CONSTITUINTES DA BELEZA ESPORTIVA: REFLEXÕES PARA A EDUCAÇÃO
}

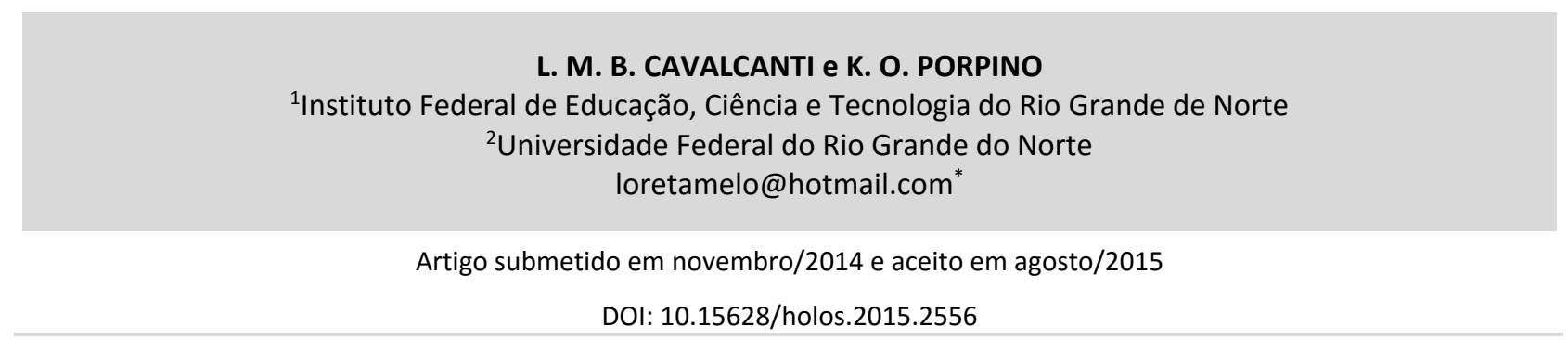

\section{RESUMO}

Pretende-se investigar as relações entre beleza, sofrimento e dor na Ginástica Rítmica (GR). Compreende-se que as construções de beleza, sofrimento e dor entremeiam-se numa complexa trama de sentidos: o corpo, fazendo com que ginasta e coreografia se constituam como uma obra de arte minuciosamente lapidada. Nesse sentido, esta investigação possui como questão de estudo: que referenciais para pensar a educação, inerentes à formulação da beleza na $G R$, emergem enquanto reflexões a partir do sofrimento e da dor? Deseja-se, a partir da abordagem fenomenológica, refletir sobre a preparação de ginastas da Ginástica Rítmica para competições esportivas buscando observar, descrever $e$ compreender a constituição da beleza na GR, enquanto esporte de natureza artística, considerando o sofrimento e a dor como elementos que a permeiam, mas que também se reverberam numa dimensão existencial e trazem referenciais para Educação. Para tanto, o presente artigo encontra-se no formato de ensaio teórico organizado a partir de dois eixos de reflexão: Sofrimento e dor que produzem beleza e Reflexões para a educação.

PALAVRAS-CHAVE: Ginástica Rítmica, Dor, Beleza, Corpo e Educação

\section{THE PAIN AND THE SUFFERING AS A CONSTITUENT OF SPORTIVE BEAUTY: REFERENCES FOR EDUCATION}

\section{ABSTRACT}

This job intend to investigate the relation between beauty, suffering and pain in Rhythmic Gymnastics (RG). In this sense, the constructions of beauty and pain interweave in a complex web of meanings: the body, causing the gymnast and her choreography constitutes as a work of art painstakingly lapidated. This research has as a matter of study: what referentials to reflect on education, inherent in the formulation of beauty on RG, emerge as reflections from the pain and the suffering? It is intended, from the phenomenological approach,
\end{abstract}

follow the preparation of the Rhythmic Gymnastics for sports competitions, searching observe, describe and understand the constitution of beauty in RG, while sport of artistic nature, considering the pain as an element that permeates, but also reverberates in an existential dimension and brings referentials for Education. To do so, this article is organized in theoretical essays from two axes of reflection format: Suffering and pain they produce beauty and Reflections for education.

KEYWORDS: Rhitmic Gymnastic, Pain, Beauty, Body e Education. 


\section{INTRODUÇÃO}

O presente texto constitui-se como um ensaio teórico e pretende investigar as relações entre beleza e dor na Ginástica Rítmica (GR) enquanto esporte de natureza artística, bem como, os referenciais educacionais aludidos a partir dessas relações.

Considera-se a dor a partir de uma categorização filosófica, ou seja, conceituada como uma das tonalidades fundamentais da vida emotiva, que costuma ser assumida como sinal de indicação do caráter hostil ou desfavorável da situação em que se encontra o ser vivo (ABAGNANO, 2012). Nesse sentido, amplia-se a perspectiva de dor que se restringe a conexões estritamente fisiológicas, embora não as negue, para os sofrimentos vividos no contexto existencial; abarcando todo o processo de constituição da obra artística esportiva, perpassando a concepção coreográfica, a rotina de treinamentos e a modificação de uma estética de vida em função dessa obra.

A beleza mencionada, dos esportes de cunho artístico, tem sua conceituação atrelada às performances corporais, numa produção de saberes aparentemente quantificados, mas que se confundem com a experiência vivenciada pelas ginastas e o teor belo para quem aprecia os exercícios.

Observa-se que as concepções de beleza na Educação Física, marcadas historicamente pela ânsia de seguir padrões, estão intimamente ligadas às performances alcançadas pelos corpos: "A beleza pretendida é a beleza do gesto realizado pelo corpo ou mesmo a beleza do corpo como produto do gesto realizado (...) os ideais de beleza se confundem entre os gestos e os corpos que os realizam" (PORPINO, 2003, p. 148). Esse padrão, por sua vez, prioriza uma concepção de estética objetivista, que tem como referência um modelo a ser seguido (PORPINO, 2004).

Para o estudioso francês Demeny, a beleza, outrora relativizada conforme o período histórico, é consequência da integridade dos órgãos e produto dos exercícios físicos. Sendo assim, a beleza aparece como a consequência de uma dada disciplina "em que o exercício físico passa a ter um lugar privilegiado. Este exercício também deve ser belo, deve expressar a harmonia geral do corpo" (SOARES, 1998, p.109).

A concepção clássica do belo, pautada na proporcionalidade, na medida, na simetria e na harmonia de formas, está relacionada a um modelo de beleza preconcebido ou a um princípio supremo. A beleza está nos objetos belos, e para serem considerados belos, estes devem se enquadrar em predefinições (SANCHÉS VÁSQUEZ citado PORPINO, 2003, P. 148-149).

Entende-se como esportes de natureza artística aqueles em que as pontuações obtidas pelos competidores se dá pelo alcance de determinadas performances corporais instituídas por modelos de gestos, mas que abrem espaço para a criação de movimentos, normalmente acompanhados por música. Nesse nicho, podemos enquadrar a Patinação Artística, o Nado Sincronizado, a Ginástica Rítmica (GR), dentre outros. Nesse texto, abordaremos a GR.

A GR, assim como a dança, aparece como manifestação da Educação Física em que a vertente estética é mais aguçada, já que, historicamente está mais ligada à Arte, campo familiar à 
Estética (PORPINO, 2003). Sendo situada, por alguns investigadores, como modalidade presente num espaço de interseção entre o Esporte e a Arte.

Alertamos que o alcance dos padrões de movimento, embora perpassem experiências estéticas significativas por parte de quem as vivencia, são constituídas a partir de uma atenção diuturna ao aprimoramento técnico dos gestos, o que é custoso para ginastas e técnicas da modalidade. Nesse processo, as construções de beleza, sofrimento e dor entremeiam-se a partir de uma complexa trama de sentidos: o corpo. Um corpo que se faz de gestos modelados e préconcebidos por um conjunto de regras prévias, mas que os recria a cada movimento. Indubitavelmente, o sofrimento e a dor se fazem presentes nesse fazer artístico, e acabam por construir beleza, uma beleza que só será alcançada a partir de uma minuciosa lapidação de gestos.

Compreender o corpo no cenário contemporâneo é uma tarefa que envolve paradoxos. Pensar sobre o corpo é também pensar sobre o modo como determinados discursos materializam-se em determinadas práticas sociais, haja vista que a nossa relação corporal com o mundo é uma contigência que marca tudo o que tem lugar fora do corpo, inclusive nas investigações científicas ou filosóficas, bem como nas intervenções educativas (NÓBREGA, 2010, p. 36).

Na disciplinarização dos corpos e na anestesia social das práticas médicas (Foucault, 1987 e 1977) a dor naturalizou-se nas intervenções femininas na busca da beleza. No âmbito do esporte performático, a potencialização dos corpos aparece como cerne da ciência do treinamento esportivo. Nesse contexto, é possível observar a figura do atleta enquanto personagem emblemático à medida que tem sua imagem mitificada pelos meios de comunicação. Fazendo com que a dor vivenciada banalize-se às rotinas de treino e transforme-se em fator determinante de performance.

Retomando a naturalização da dor, observa-se que esta mascarou-se historicamente no século XX.

A dor e o sofrimento não desaparecem, retraem. Mas para onde? Para dentro das prisões e para os espaços de enclausuramentos onde as disciplinas encontram, à primeira vista, seu habitat natural. Se o modelo normativo, constituído ao redor das disciplinas, alojou-se, pelas razões explicitadas em Vigiar e Punir (1975), em torno da prisão, a prisão não abdicou de suas tradicionais funções punitivas entre as quais a de fabricar a dor e o sofrimento. Algumas delas são como que clássicas: o isolamento, o silêncio, os pequenos espancamentos cotidianos, o violento assédio sexual, a contaminação de toda sorte, as ameaças de delação, os deslocamentos arbitrários de celas e de estabelecimentos penitenciários etc (ADORNO, 2000, p. 28-29).

Os mecanismos de dor disciplinares minimizam e escondem as punições corporais abrindo espaço para a constituição de corpos dóceis (FOUCAULT, 1987), no entanto, o esporte é um dos âmbitos em que o sofrimento e a dor tornam-se capazes de encontrar sua justificação social. 0 atleta convive com estes, desde que os fatores que interfiram negativamente no seu desempenho possam ser anulados ou estabilizados. 
No caso dos esportes com características eminentemente artísticas, a exemplo da nossa Ginástica Rítmica, a busca pela beleza pautada em técnicas esportivas especializadas configura o direcionamento das performances.

Vale lembrar que a Ginástica Rítmica é uma modalidade que teve sua subjetividade artística sobrepujada pela racionalidade esportiva, pois seus objetivos de reforçar os estereótipos femininos da origem do século $X X$ foram transfigurados pelas exigências competitivas. No entanto, continuou-se a essência de uma prática resguardada ao gênero feminino, abarcando espaços para a expressão artística que vai além do enquadramento em regras e códigos, como preconiza sua vertente artística. Arte ilustrada por Duarte Jr apud ROSSETE (1997, p. 277) como:

\begin{abstract}
uma tentativa de concretizar em formas o sentimento humano. Está vinculada, portanto à personalidade do artista e à sua integração no contexto sociocultural, político e histórico. Sob esse ponto de vista, a arte não pode ser regida por regras rígidas, explicitamente formuladas e ordenadas. $\mathrm{O}$ artista não se escraviza a códigos de nenhuma natureza.
\end{abstract}

Considerando esse cenário de primeiras reflexões acerca da dor, da beleza e da GR, esta investigação possui como questão de estudo: Que referenciais para pensar a educação, inerentes à formulação da beleza na GR, emergem enquanto reflexões a partir do sofrimento e da dor?

Ressalta-se que estando o presente artigo no formato de ensaio teórico, organizou-se dois eixos de reflexão: "Sofrimento e dor que produzem beleza" e "Reflexões para a Educação". No intuito de iniciarmos as reflexões, nos deteremos a seguir em adentrar nas incursões da problemática apresentada.

\title{
2 SOFRIMENTO E DOR QUE PRODUZEM BELEZA
}

Concordamos com a ideia de que a dor sentida não é um simples fluxo sensorial, mas uma percepção que suscita primeiro a relação do sujeito com o mundo e da experiência acumulada a esse respeito. "Ela não escapa à condição antropológica das outras percepções. É simultaneamente experimentada e avaliada, integrada em termos de significado e valor. Nunca puramente fisiológica, a dor pertence à esfera simbólica" (BRETON, 2013B, p. 16).

A dor é uma incisão de sagrado no sentido em que arranca o homem de si mesmo e o confronta com seus limites. Mas ela é uma forma caprichosa disso, arde com uma crueldade sem nome. No entanto, se é moralmente controlada ou se é superada, a dor amplia o olhar do homem, lembra-lhe o valor da existência, o sabor do instante que passa. Tudo depende do significado que o homem lhe confere. Se tira o gosto de viver que o acomete, a dor revigora de modo contrário quando se afasta. Ela restaura o fervor de existir. É um memento mori que traz o homem de volta ao essencial (BRETON, 2013B, p.20).

Esse fervor de existir, o momento que o ser humano lembra-se que vive, é experimentado continuamente na exaustão do treinamento corporal, a cada lembrança de etapa cumprida, desde a finalização de uma sessão diária, passando pelo término de composição de uma série, até a finalização de um período competitivo. De modo que, beleza e dor perpassam as concepções coreográficas e a preparação para as competições nos esportes de natureza artística, no nosso caso, a Ginástica Rítmica (GR), confundindo-se com a alta performance. 
Porém, a dor convive em diferentes práticas corporais sistematizadas da contemporaneidade, de modo que nem é exclusividade dos Esportes de alto rendimento, muito menos daqueles de natureza artística. A hipervisibilidade dos corpos provocaram grandes preocupações com a beleza na contemporaneidade. O culto ao corpo vincula-se cada vez mais a abertura de espaços e intervenções tecnológicas destinados à modelação deste. Nesse contexto, a dor mediada pela tecnologia nos investimentos sobre o corpo encontra positividade na sensação do dever cumprido, adquirindo caráter legitimador, justificando-se como símbolo de merecimento pelo ideal a ser atingido, ou seja, o culto contemporâneo ao corpo "entrelaça discursos pela promoção da saúde com dispositivos de conformação somática vinculados, entre outros, à performance, à instrumentalização orgânica e celebração a juventude" (VAZ, 2007, p. 01).

Nesse sentido, a vinculação entre padrões estéticos e o sofrimento para busca-los parece validar a presença da dor e do sofrimento sob a égide da premissa No pain, No gain (sem dor, sem ganhos). Ao esporte pertence não apenas o impulso à violência, mas também a suportá-la e tolerá-la" (ADORNO citado por VAZ, 2001, p.08).

A dor proveniente do treinamento remete ao sacrifício feito em nome do rendimento esportivo. E assim sendo, o autocontrole exigido pelo atleta, aproxima-se, de acordo com Vaz e Gonçalves (2012, p. 8) de um indivíduo, que,

\begin{abstract}
para se tornar sujeito precisa sacrificar sua própria natureza, seu corpo, reprimindo suas pulsões e desejos em nome da racionalidade, premissa fundamental para a civilização ocidental. Talvez o esporte leve esse processo a planos muito elevados, já que nele o domínio de si é exigência para sua concretização, tanto na esfera orgânica, como subjetiva, já que os sentimentos (sejam eles dores, medo, nervosismo, euforia etc) devem ser suplantados em nome da performance e do resultado. $O$ atleta que se deixa dominar por suas paixões indeterminadas torna-se fraco e no esporte não há lugar para a debilidade, uma vez que é espaço de construção de uma identidade guerreira e sempre pronta para o desafio, para o combate. $\mathrm{O}$ aprendizado para suportar e mesmo para gozar com a dor se dá nos treinamentos.
\end{abstract}

Nessa compreensão, a dor, seja ela propriamente dita ou enquanto abdicação de uma estética de vida impulsionada por impulsos e desejos humanos é tida como uma presença constante na vida de atletas de alto rendimento, representando a busca e superação de limites, que por sua vez, incutem a construção da melhor forma atlética possível (RUBIO e MOREIRA, 2007).

A dor, "experiência sensitiva e emocional desagradável, uma das informações aferentes mais importantes para a preservação da vida." (RUBIO; MOREIRA, 2007, p. 927), não corresponde apenas a uma visita insistente, mas a uma sensação que deve ir sendo vencida paulatinamente, devendo, mesmo que indique uma possível expressão moral de dever cumprido, ser esquecida.

No contexto da dor e do oferecimento ao sacrifício, o treinamento o representa, na medida em que o atleta é o sacrificante que oferece seu próprio corpo ao sacrifício, dilacerandoo em nome dos benefícios futuros. O técnico é o sacrificador, aquele que guia o sacrificante até o resultado esperado (VAZ e GONÇALVES, 2012). “Como se sabe, a dor não é uma 'aliada' do treinamento corporal, mas, do ponto de vista subjetivo, o inimigo a ser combatido, superado, 
suportado, ignorado - ou ainda, num registro mais fronteiriço, a experiência a ser glorificada" (HANSEN; VAZ, 2004, p. 142).

Nessa perspectiva de relacionamento entre treinamento e dor, em que o esporte performance vem operando a partir da potencialização dos corpos, é possível observar que nos esportes de cunho artístico essa operacionalização se dá pela constituição da beleza vislumbrada na criação de suas regras e das transgressões do corpo, nesse sentido, a beleza está diretamente relacionada a dor e a potencialização desses corpos.

Sendo assim, partindo das análises realizadas em estudos anteriores, observamos que os caminhos da beleza na Ginástica Rítmica esboçaram uma construção de relações de poder-saber, pois se constituíram a partir de mecanismos de coerção-resistência dos corpos ante os objetivos pedagógicos e militares primordiais e as regulamentações esportivas. Para tanto, tomamos algumas das reflexões sobre poder de Foucault $(1971,1979,1987)$ e sua relação com a produção de saberes, pois, naquele momento, acreditamos na perspectiva de uma intervenção corporal que não acontece flutuando em um plano ideológico, em um poder não é hierarquizado, pois das relações de poder nos inteiramos em proporções diferenciadas. Ou seja, o poder se inscreve no corpo, que o denuncia e ao mesmo tempo o exerce.

Tecendo uma crítica às análises marxistas, cujo entendimento do poder privilegiar sua condição ideológica, Foucault (1979, p. 147-148) esclarece:

$\mathrm{Na}$ verdade, nada é mais material, nada é mais físico, mais corporal que o exercício do poder... Qual é o tipo de investimento do corpo que é necessário e suficiente ao funcionamento de uma sociedade capitalista como a nossa? Eu penso que, do século XVII ao início do século XIX, acreditou-se que o investimento do corpo pelo poder devia ser denso, rígido, constante, meticuloso. Daí esses terríveis regimes disciplinares que se encontram nas escolas, nos hospitais, nas casernas, nas oficinas, nas cidades, nos edifícios, nas famílias...

Foucault (1979) nos clarifica que o poder está disseminado na sociedade, nas várias relações, pois quem se sujeita não é sempre submisso, produz poder também. Ressalvamos que as observações sobre poder foucaultianas, não são arguidas de concepções maniqueístas, ocorrem em uma rede complexa nas relações sociais.

É no corpo onde ocorrem os controles da sociedade, as relações de poder, não por ideologias "sobrevoantes" (Foucault, 1979), mas por um discurso visceral, que adequa, expande, endireita, amplia, poda e produz conhecimento.

O corpo, tornando-se alvo dos novos mecanismos de poder, oferece-se a novas formas de saber. Corpo do exercício mais do que da física especulativa; corpo manipulado pela autoridade mais do que atravessado pelos espíritos animais; corpo de treinamento útil e não da mecânica racional, mas no qual por essa mesma razão se anunciará um certo número de exigências de natureza e de limitações regionais (FOUCAULT, 1987, p. 132).

Portanto, o campo de incidência e projeção do poder é o corpo. As pedagogias corporais, por sua vez, são as práticas sociais, históricas e datadas que são responsáveis por produzir os sentimentos, as aparências e a fisiologia dos nossos corpos. 
O corpo é resultado provisório de diversas pedagogias que o conformam em determinadas épocas. É marcado e distinto muito mais pela cultura do que por uma presumível essência natural. Adquire diferentes sentidos no momento em que é investido por um poder regulador que o ajusta em seus menores detalhes, impondo limitações, autorizações e obrigações, para além de sua condição fisiológica, um poder que não emana de nenhuma instituição ou indivíduo ou muito menos se estabelece pelo uso da força, mas sim pela sutileza de sua presença nas práticas corporais da vida cotidiana (FRAGA, 1999, p. 213).

Assim, as pedagogias corporais correspondem às formas com que os seres humanos paulatinamente esculpem os gestos através dos tempos, culminando numa composição constante e inacabada da cultura de movimento. Tomamos aqui o termo Cultura de Movimento como "conceito que expressa diferentes compreensões e usos do corpo em uma determinada cultura ou sociedade" (NÓBREGA, 2003, p. 134), e como forma de entendermos a Ginástica Rítmica em suas interconexões com a história, os costumes, as necessidades humanas e as crenças de um determinado povo.

As técnicas de exercício do poder que nortearam os conhecimentos do corpo voltado a si mesmo foram as disciplinas (FOUCAULT, 1987), já mencionadas anteriormente. Estas configuraram sentidos atrelados à produção de discursos. Desse modo, pensamos a beleza a partir da trama de discursos construídos pelas relações de saber-poder e dos investimentos do corpo na ginástica.

Para aferir o quão um discurso é penetrado na vida social é preciso observar a naturalidade com que ocorre sua inscrição nos corpos, pois quanto mais natural, mais seus efeitos são imperceptíveis e maior é sua força do ponto de vista do mecanismo de poder que o induziu (FRAGA, 2000). Tal fato abre a perspectiva para pensarmos os efeitos do poder na forma com que percebemos a beleza, pois há concepções que norteiam nossos "gostos" e não nos damos conta disso. A GR, por exemplo, é uma modalidade que nasceu para ser bela, beleza préconcebida, e assim segue seu dever. A beleza é uma condição, está posta, é "natural" à GR, mesmo que o termo nem sempre esteja explicitado nos seus diversos discursos.

Para que os aspectos apresentados fossem se constituindo, a Ginástica Rítmica percorreu uma trilha norteada pela sua mais emblemática vertente: a beleza. Esta, sempre foi contemplada na ginástica, carregada pela disciplina coercitiva dos corpos (FOUCAULT, 1979), pela retidão, pela higiene, pela harmonia de formas, pela simetria. Por um conjunto de prescrições necessárias para se extrair um resultado esperado, para produzir, através do corpo um conhecimento sobre ele mesmo. A produção da beleza teve, sobretudo, a ingerência artística como fundamento para sua criação, a exemplo da dança, do teatro e da música.

Com isso, temos uma ginástica que se pauta no modelo, mas se afirmou nas concepções da Arte Moderna, movimento em que os modelos são criticados; se pautou na expressão do sexo feminino, mas procria diferenciações entre os sexos; se pautou na beleza dos movimentos naturais, mas se afirma na performance enquanto categoria dessa beleza. Caráter ambíguo, como o poder expresso por Foucault (1979), que ao mesmo tempo em que se exerce, cria mecanismos de fuga, cria um contra-poder.

Esse espaço fechado, recortado, vigiado em todos os seus pontos, onde os indivíduos estão inseridos num lugar fixo, onde os menores movimentos são 
controlados, onde todos os acontecimentos são registrados, onde um trabalho ininterrupto de escrita liga o centro e a periferia, onde o poder é exercido sem divisão, segundo uma figura hierárquica e contínua, onde cada indivíduo é constantemente localizado, examinado e distribuído entre os vivos, os doentes e os mortos - isso tudo constitui um modelo compacto do dispositivo disciplinar (FOUCAULT, 1987, p. 163).

Esse dispositivo disciplinar é caracterizado por Foucault (1987, p. 169) como nicho onde o poder se torna presente e visível em toda parte "inventa novas engrenagens; compartimenta, imobiliza, quadricula".

O processo pelo qual a ginasta é julgada, na situação da competição esportiva, passa pela semelhança do dispositivo disciplinar assinalado por Foucault, por compreender justamente duas das características básicas do mecanismo disciplinar: a vigilância e o registro (Foucault, 1979).

A disciplina é o conjunto de técnicas pelas quais os sistemas de poder vão ter por alvo e resultado os indivíduos em sua singularidade. É o poder de individualização que tem o exame como instrumento fundamental. $O$ exame é a vigilância permanente, classificatória, que permite distribuir os indivíduos, julgálos, medi-los, localizá-los e, por conseguinte, utilizá-los ao máximo (FOUCAULT, 1979, p. 107);

A Ciência do Treinamento Esportivo compele uma periodização do treinamento da ginasta determinando períodos, ciclos, horários, quantidades, intensidades, testes e intervalos (LAFFRANCHI, 2001), que são devidamente registrados a cada dia e avaliados através de gráficos. Sendo assim, ao passar do estado de treinamento para o competitivo, os registros continuam, e, ao sair da quadra após uma apresentação, a ginasta terá todo o mapeamento dos seus movimentos descritos nas fichas de avaliação da arbitragem.

A estética da performance, em muitos momentos, sobrepuja a estética da vida. Ou seja, há "a negação de outras estéticas corporais e vivências estéticas da própria ginasta, presentes por exemplo nas ações cotidianas relativas à alimentação, ao convívio familiar, às formas de perceber e aceitar o próprio corpo" (PORPINO, 2004, p. 129). É o que reflete esta autora em artigo que disserta sobre as concepções estéticas do treinamento esportivo da GR. E complementa referindo-se à relação paradoxal entre essas estéticas, pois, "ao mesmo tempo em que o sacrifício é justificado pela concretização de uma estética esperada é na negação de uma estética de vida que esse sacrifício é realizado" (PORPINO, 2004, p. 128). A ginasta "abandona" sua vida para garantir sua resignificação por meio da dor, do uso de um corpo constantemente utilitário em prol do sonho de se tornar uma campeã.

O poder, longe de impedir o saber, o produz. Se foi possível constituir um saber sobre o corpo, foi através de um conjunto de disciplinas militares e escolares. É a partir de um poder sobre o corpo que foi possível um saber fisiológico, orgânico. $O$ enraizamento do poder, as dificuldades que se enfrenta para se desprender dele vem de todos esses vínculos. É por isso que a noção de repressão, à qual geralmente se reduzem os mecanismos do poder, me parece muito insuficiente, e talvez até perigosa (FOUCAULT, 1979, p. 148-149).

Mesmo em face de todas as críticas realizadas em razão da disciplinarização dos corpos, consequente controle dos impulsos e resistência à dor, também foi possível refletir que estes, de 
modo algum, sujeitam-se ao enclausuramento escravizado, já que encontram linhas de fuga para a produção de saberes. Ao nosso ver, a interface artística da Ginástica Rítmica favorece esse processo.

E assim constituída a relação saber-poder possibilitada pela disciplina e permeada pela dor, vem à tona a construção da criatividade, pois, a transgressão é o instrumento necessário para a liberdade-criação. Com a perspectiva da criação e de construção de conhecimento aludidas pelas relações de saber-poder para a constituição artística, evidenciadas no treinamento corporal e na dor, buscaremos refletir sobre referenciais educacionais no próximo tópico.

\section{REFLEXÕES PARA A EDUCAÇÃO}

A obra artística referendada pelo presente estudo é o próprio corpo da ginasta em movimento, que constitui sua atmosfera pelas suas formas, aparências, oscilações no espaço e implementos. A ginasta em seu exercício é objeto estético, fundada pela concepção de sua coreografia entremeada a sua expressão. Porém, vale considerar que a ginasta pendula entre dois extremos, o da expressão pessoal e o da técnica inerente à $G R$, ao mesmo tempo em que não pode se desviar da técnica pode criar e se expressar dentro desta. Os estilos constituídos pelos países, técnicas e ginastas, se expressam como os modos com que os moldes da GR foram transgredidos e transformados, o que por sua vez caracterizaram a constituição da própria GR. Esse fenômeno é comum a outras práticas corporais sistematizadas, como os esportes, e se constitui como de suma importância para o enriquecimento da Cultura de Movimentos e produção de saberes na área da Educação Física.

O corpo não é uma massa material inerte e a causalidade linear, baseada no esquema estímulo-resposta, não se apresenta como a maneira mais apropriada de compreensão do universo corpóreo. Por sua vez, a sensação e a percepção não são elementos inferiores à evidência racional, aos conceitos lógicomatemáticos, sendo imprescindíveis ao processo de conhecimento. Com esses argumentos, busca esclarecer a relação entre corpo e consciência, inaugurando uma nova possibilidade de compreensão desse fenômeno: a análise existencial, privilegiando o mundo das experiências vividas como plano primeiro da configuração do ser e do conhecimento (NÓBREGA, 2010, p. 52).

Porpino (2006), à luz de Nieztsche, refere-se a vontade de potência do corpo como uma força criativa proporcionada pela arte, de modo a aumentar sua força criativa e retomando estados de prazer.

Dançando, muitos seres humanos puderam (e ainda podem) expressar a plasticidade inerente ao corpo, maleabilidade de lidar criativamente com situações que pareciam petrificadas por uma verdade irrefutável (...). Para usar uma expressão nietzscheana, é a vontade de potência, capaz de transformar o instituído fazendo emergir do próprio corpo a possibilidade de transformação (PORPINO, 2006, p. 50).

E continua sua análise evidenciando o mundo das aparências nietzscheano em sua realidade mutante e contraditória, fazendo refletir sobre a coexistência do corpo real e imagético, que se resignificam e não negam a realidade ambígua da corporeidade (PORPINO, 2006). 
Pensar a corporeidade faz-nos descobrir essa essência dialógica do ser humano que guarda em sia a possibilidade de conviver com realidades opostas, de não se resumir a apenas um aspecto da exisência e de transitar por caminhos que aparentemente não se cruzam. Em se tratando dessa peculiaridade, qualquer tentativa de qualificar os seres humanos com adjetivações fixas ou de propor mudanças fundadas em substituições de posições antigas por posições novas pode significar a tomada de posturas maniqueístas que em nada coadunam com a realidade mutante e cambiante do ser humano (PORPINO, 2006, p.52).

A corporeidade transcende as compreensões simplistas das práticas corporais a medida que não se restringe às limitações teóricas e lineares destas. Ao contrário, enquanto condição existencial do ser humano amplia-se nas contradições e angústias dos contextos, nas dores e prazeres do fazer, nas fruições e desafios do vivenciar, e, principalmente, na justa estimulação entre a percepção do olhar ao mundo e o convite à apreciação/apropriação dos saberes corporais que enfatizam a produção de conhecimento.

Nesse contexto, de contradições, complexidades e até paradoxos, tais quais as realidades vividas, a dor é inerente à existência humana. Sendo assim, a dor experenciada e compreendida não como elemento de coerção, mas como dimensão existencial, pode aguçar o entendimento da sua razão de existir, da ética, do respeito à dor do outro, pois, do mesmo modo que a criação de uma obra de arte é capaz de arrebatar o sujeito a partir de sua experiência estética, este coloca-se disponível a perceber o outro em suas dores, sofrimentos e tragédias. Desse modo, a dor também produz saber, é parte da existência e portanto negá-la na educação seria negar o corpo em sua característica de ser ambíguo

Sentir dor não nos torna indolor, assim como não senti-la não nos faz perder a sensibilidade. Porém, compreender os sentidos que se entremeiam na sua constituição permite racionalizá-la, e assim sendo, amplifica-se o entendimento da corporeidade como única condição de apreensão desse mundo.

A dor e o sofrimento, os quais mencionamos, não se classificam apenas como um conjunto de conexões neurológicas, numa perspectiva centrada nos processos biológicos, nos referimos aqui a um sofrimento que implica por exemplo na capacidade de construir algo, uma obra artística por exemplo.

Nesse caminho, Merleau-ponty esclarece que não cabe dizer que:

O corpo é feito de duas faces, sendo uma, a do 'sensível', solidária com o resto do mundo: nele não há duas camadas ou duas faces, e ele não é, fundamentalmente, nem apenas coisa vista, nem apenas vidente, é a Visibilidade ora errante, ora reunida e, sob esse aspecto, não está no mundo, não retém, como num recinto privado, sua visão do mundo: vê o próprio mundo, o mundo de todos, e sem ter que sair de 'si', porque não é inteiro, porque suas mãos, seus olhos, nada mais são do que essa referência do visível, de um tangível medida a todos os seus semelhantes, dos quais recolhe o testemunho, por um passe de mágica que é a própria visão e o próprio tato (MERLEAU-PONTY, 2009, p. 134).

Portanto, tudo o que se diz do corpo sentido, repercute diretamente sobre o todo sentido que faz parte e sobre o mundo (MERLEAU-PONTY, 2009). 
A educação da sensibilidade, o processo de se conferir atenção aos nossos fenômenos estésicos e estéticos, vai se afigurando fundamental não apenas para uma vivência mais íntegra e plena do cotidiano, como parece ainda ser importante para os próprios profissionais da filosofia e da ciência, os quais podem ganhar muito em criatividade no âmbito de seu trabalho, por mais racionalmente "técnico" que este possa parecer. Uma educação que reconheça o fundamento sensível da nossa existência e a ele dedique a devida atenção, propiciando o seu desenvolvimento, estará, por certo, tornando mais abrangente e sutil a atuação dos mecanismos lógicos e racionais da operação da natureza humana (DUARTE JUNIOR, 2010, p. 171).

Refletindo acerca dessa educação da sensibilidade que considera o corpo e a existência, que concluiremos esse texto.

\section{CONSIDERAÇÕES FINAIS}

A GR, enquanto esporte de natureza artística, tem a dor como elemento que a permeia, mas que também se reverbera numa dimensão existencial e traz referenciais para Educação. Pois, qualquer dor, até mesmo a mais modesta, leva à mudança do ser, à metamorfose, projetase numa dimensão inédita da existência, abrindo no ser humano uma metafísica que provoca uma reviravolta no modo habitual de sua relação consigo mesmo, com os outros e com o mundo (BRETON, 2013B).

Consideramos, a partir da nossa análise da dor, que as configurações dos gestos da GR ocorreram e ocorrem através de uma hibridação de técnicas que especificam gestos pautados nas performances, na extrapolação de limites corporais de flexibilidade, potência, habilidade com aparelhos e consciência corporal aguçada em todos os movimentos, e, que por esses aspectos a GR se constitui como uma prática permeada pela dor e pela composição artística simultaneamente. Constatamos ainda que as formas de controle corporais e regulamentações são constantemente extrapoladas, implicando numa potencialização dos graus de dificuldade e na exacerbação das técnicas existentes, ou seja, a produção de conhecimento. Entretanto, as transcendências não ocorrem somente na linha da acentuação do alto rendimento esportivo. As ginastas conseguem estilizar seus movimentos e exercícios, conseguem produzir uma obra que é colocada para apreciação.

Desse modo, a beleza na GR se dá justamente na possibilidade da criação do estilo próprio, na possibilidade de viver o improviso e o imprevisto, na possibilidade de ser original, de sensibilizar o público - porque o poder e a dor criam saberes e o corpo, como extrapolador, sempre criará novas formas de ser belo. Isso quer dizer que, mesmo regrada, a ginasta pode criar, ser original e bela à sua maneira. Isso significa que a Educação Física, campo de intervenção pedagógica, pode conviver com esse corpo que nunca é somente submisso.

A beleza do alto rendimento encanta e suscita a produção de novos encantos. Para a Educação Física não é possível transplantar os modelos, mas aprender com o corpo que recria, subverte, faz diferente, é original apesar da regra. É preciso lidar com o determinado e com ele produzir outros saberes.

Transcender é uma necessidade da Educação. O incidir do poder e da dor sobre o corpo arranca frutos que transcendem essa incidência, dessa forma, saberes são produzidos. Acreditamos que as contribuições da ginástica, Ginástica Rítmica no nosso caso, para pensar a 
pedagogia do corpo, ocorram a partir dessa linha de pensamento. Na ginástica aprendemos pela ultrapassagem de limites, pela aceitação de desafios, somos convocados a suplantar sempre aquilo que já fomos capazes de produzir. A perfeição é uma qualidade requerida, mas não é condição para a prática da GR. É possível que, com a ampliação do olhar sobre essa modalidade proposta por este trabalho, qualquer um, numa intervenção pedagógica, possa apreendê-la a partir de suas próprias possibilidades, a partir dos seus alcances.

\section{REFERÊNCIAS BIBLIOGRÁFICAS}

1. ABAGNANO. Dicionário de Filosofia. São Paulo: Martins Fontes, 1998.

2. ADORNO, S. Dor e sofrimento: presenças ou ausências na obra de Foucault? Cadernos da FFC. V.09, N.01, 2000.

3. DUARTE JR. J. F. O sentido dos sentidos: a educação (do) sensível. Curitiba: Criar edições, 2001.

4. FOUCAULT, M. A ordem do discurso. Disponível em: http://www.unb.br/fe/tef/filoesco/ foucault/ordem.html. 1971.

5. _. Microfísica do poder. Org. e Tradução Roberto Machado, 22a ed. Rio e Janeiro: Edições Graal, 1979.

6. _ _ Vigiar e punir: história da violência nas prisões. Tradução Raquel Ramalhete.31ạ ed. Petrópolis: Vozes, 1987.

7. FRAGA, A. B. Pedagogias do corpo: marcas de distinção das práticas escolares. In: KRUG, Andréa e Azevedo, José Clóvis. Século XXI: Qual o conhecimento? Qual o currículo? Petrópolis: Vozes, 1999.

8. Corpo, identidade e bom-mocismo: cotidiano de uma adolescência bem comportada. Belo Horizonte: Autêntica, 2000.

9. LAFFRANCHI, B. Treinamento Desportivo aplicado à Ginástica Rítmica. Londrina: Unopar Editora, 2000.

10. LE BRETON, D. Antropologia do corpo. Petropolis, RJ: Vozes. 2013A.

11. Antropologia da dor. São Paulo: Fap-Unifesp, 2013B.

12. MELO, J. P. Sacrifícios do Corpo no Esporte. In: LUCENA, R. F. E SOUZA, E. F. (orgs.) Educação Física, Esporte e Sociedade. João Pessoa: Editora UFPB, 2000.

13. MERLEAU-PONTY, M. O visível e o invisível. São Paulo: Editora Perspectiva, 1992.

14. NÓBREGA, T. P. Para uma teoria da corporeidade: Um diálogo com Merleau-Ponty e o pensamento complexo. Tese de doutorado, Piracicaba, SP, 1999.

15. . Uma fenomenologia do corpo. São Paulo: Editora Livraria da Física, 2010.

16. Merleau-ponty: o filósofo, o corpo e o mundo de toda gente! Comunicação oral no Congresso Brasileiro de Ciências do Esporte, 2003.

17. PORPINO, K. de O. Interfaces entre corpo e estética: (re)desenhando paisagens epistemológicas e pedagógicas na Educação Física. In: LUCENA, R. F. e SOUZA, E. F. (orgs.) Educação Física, Esporte e Sociedade. João Pessoa: Editora UFPB, 2003. 
18. Treinamento da Ginástica Rítmica: reflexões estéticas. Revista Brasileira de Ciências do Esporte. Campinas: V. 26, N.1, Setembro, 2004.

19. Dança é Educação: interfaces entre corporeidade e estética. Natal, EDUFRN, 2006.

20. ROSSETE, E. de F. C. O julgamento da Ginástica Rítmica Desportiva. In SOUSA, E. S. e VAGO, M. M. (orgs.) Trilhas e Partilhas: Educação Física na cultura escolar e nas práticas sociais. Belo Horizonte: Gráfica e Editora Cultura, 1997

21. RUBIO, K; MOREIRA, F. de G. A representação de dor em atletas olímpicos brasileiros.". Revista Dor, vol. 8, n. 1, São Paulo, Âmbito Editores, p. 926-935, 2007.

22. SOARES, C. L. Imagens da educação no corpo: estudo a partir da ginástica francesa no século XXI. Campinas, SP: Autores associados, 1998.

23. VAZ, A. F; BASSANI, J. J; TORRI, G. Dor e tecnificação no contemporâneo culto ao corpo. Revista Pensar a prática, 2007.

24. VAZ, A. F; GONÇALVES, M. C. Educação do corpo, dor e sacrifício: um estudo com os competidores de atletismo. Revista Ibero americana de Edución, 2012. 